\title{
ALGUNAS CONSIDERACIONES SOBRE LA TEORÍA PEDAGÓGICA DE LEIBNIZ *
}

Ezequiel Téllez Maqueo

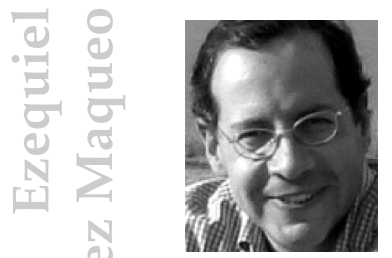

Doctorado cum laude en Filosofía y Letras, Universidad de Navarra. Licenciatura en Filosofía, Universidad Panamericana. Profesor, conferencista e investigador en el terreno de las humanidades clásicas. Ex-editor asociado de Tópicos, revista de Filosofía de la Universidad Panamericana. Miembro fundador de la Sociedad Internacional Tomás de Aquino, sección México, D.F. Es autor de los siguientes libros: Las cuestiones disputadas acerca del mal en Santo Tomás (Eunsa, Pamplona, 1997); Las cuestiones disputadas acerca del alma según Tomás de Aquino (Eunsa, Pamplona, 2001), y de más de treinta artículos especializados en revistas de filosofía y difusión de la cultura como Intersticios; Medievalia; Espíritu; Acta Academica, etcétera. Correo electrónico: [detellez@up.edu.mx].

\section{RESUMEN}

El propósito de estas líneas es desarrollar algunos consejos de interés para la ciencia pedagógica propuestos por Leibniz, obtenidos de una de sus obras más representativas para la pedagogía, el Nuevo método para aprender y enseñar la ciencia del derecho (1667), en cuya primera sección Leibniz se revela como un brillante consejero sobre aquellos conocimientos y habilidades que niños y jóvenes deben aprender desde los cinco hasta los dieciocho años; las materias en las que necesitan ser instruidos, y los aspectos aristotélicos de la enseñanza relacionados con la pedagogía de Leibniz. Recomendaciones ingeniosas y propuestas inteligentes alcanzadas a través de su propia experiencia, reflejan en él a un profesor bien dispuesto para el conocimiento de un cuerpo esquemático de verdades relativas a todos los campos del saber.

* Recepción: marzo 14, 2010/Aprobación: agosto 15, 2010. 
Palabras clave: Leibniz; didáctica; mnemotecnia; historia de la pedagogía.

\begin{abstract}
The aim of these lines is try to develop some advices of interest to pedagogical science given by Gottfried Wilhelm Leibniz (1646-1716), obtained from one of his most representative works concerning teaching, i.e., the Nova Methodus discendae docendaeque Jurisprudentiae (1667), whose first section reveals Leibniz like a suggestive counselor about those knowledge and skills that should be acquired by kids and young people from 5 to 18 years old; the subjects in which they need to be instructed, and those aristotelian aspects of teaching related to leibnician pedagogy. Smart suggestions and discerning proposals attained through his own experience show Leibniz as a well disposed teacher to know an schematich body of truths concerning all fields of learning.
\end{abstract}

Key words: Leibniz; Didactic; Mnemonic; History of Pedagogy.

\title{
INTRODUCCIÓN
}

Al igual que Aristóteles, Gottfried Wilhelm Leibniz (1646-1716) es uno de los pensadores intelectualmente más versátiles que ha producido la humanidad. Poseedor de una inteligencia extraordinaria y de una gran capacidad de asimilación y sistematización del saber, adquirió múltiples conocimientos en calidad de autodidacto, favorecido por el hecho de que su padre y su abuelo eran profesores universitarios, y porque desde niño entró en contacto con la biblioteca familiar a través de la cual pudo adquirir un profundo amor por las letras, las ciencias y la cultura en general. Es bien conocido su trabajo filosófico como lógico y metafísico, como fundador del cálculo infinitesimal (lugar que le disputó simultáneamente Newton), como erudito y enciclopedista (con perfecto dominio del alemán, francés, inglés, italiano, hebreo, griego y latín, los que había aprendido desde antes de los 12 años), jurista, diplomático y un sabio consejero al servicio de Juan Federico de Braunschweig-Luneburg, duque de Hannover, en cuya corte sirvió como bibliotecario e historiógrafo de 
palacio. Después de haber viajado por Europa, de conocer a personajes como Newton, Spinoza, Leeuwenhoeck, y de haber trabado relación con múltiples príncipes, murió en 1716 a los 70 años en plena soledad.

Además de ciencia y filosofía, sus múltiples intereses por diversos campos del conocimiento lo llevaron a cultivar el arte de aprender, a partir de su propia experiencia como autodidacto, y a cultivarlo con base en un fino sentido de la observación y del detalle ${ }^{1}$. Estas inquietudes por una metodología didáctica fueron asentadas por escrito, no en una obra propiamente pedagógica, sino en una obra curiosamente jurídica conocida como el Nuevo método para aprender y enseñar jurisprudencia ${ }^{2}$, publicado en 1667, con edición crítica de Zuner. Escrito cuando acababa de licenciarse en jurisprudencia en Altdorf - en un latín alambicado, sumamente erudito y por momentos barroco (lo que refleja la vastedad de los intereses que persiguió su autor hasta el fin de sus días) - y plagado de incontables helenismos (methodus, syntaxeos...), Leibniz expone en esta obra de la que no existe hasta el momento (2009) versión íntegra al español, los principios generales de su doctrina pedagógica, acompañada ésta de una serie de observaciones y recomendaciones, entre originales unas y otras que, por un momento, nos recuerdan exceptis excipiendis los principios aristotélicos de la educación.

El objeto de esta exposición consiste, precisamente, en explicar los puntos más relevantes de su doctrina para la ciencia pedagógica (a partir de una traducción personal y directa del latín al castellano de los pasajes más significativos de dicha obra), mostrando cierta afinidad de Leibniz

1 Cfr. Más detalles sobre la versatilidad de sus intereses intelectuales y científicos, robustecidos principalmente durante su estadía en París, pueden consultarse en: J. Moreau, «Leibniz a Paris» en Teoresi, p. 201-221.

2 Leibniz, Nova methodus discendae docendaeque jurisprudentiae: ex artis Didacticae Principiis in parte Generali praemissis, experientiaeque Luce En este artículo, nos hemos hecho cargo de la traducción directa del latín al castellano sobre el texto de la edición crítica disponible (Francofurti: Johannis Davidis Zunneri, 1667, 364 p.). Las citas referentes a esta obra se citan a lo largo del presente artículo mediante la abreviatura $\mathbf{N M}=$ Nova Methodus. El número I romano que aparece enseguida significa que una cita corresponde a la Parte primera o parte general. Posteriormente se cita el número de inciso (§), y al final la página en que aparece dicha cita en la edición crítica de Zunner. 
respecto a Aristóteles - en particular respecto al concepto aristotélico de hábito como una vía legítima y fundamental de aprendizaje para los humanos-, lo mismo que la dimensión lúdica del conocimiento y, finalmente, la erudición de la que se sirvieron ambos filósofos en sus obras al explicar sus doctrinas.

\section{RELACIÓN ENTRE ENTRENAMIENTO Y HÁBITO}

Es sabido que la distinción filosófica entre «educación» y «entrenamiento» ${ }^{3}$ encuentra su fundamentación histórica en la distinción medieval entre las Artes Liberales, que son la base de la paideia griega, y las Artes Mecánicas, que son lo más próximo en el Medioevo a lo que hoy podría considerarse un entrenamiento (trainning). La educación - relacionada más con el estudio y la enseñanza de un cuerpo de conocimientos formativos del carácter, y que ensanchan el espíritu hasta enseñarnos a ver lo relevante de la vida- se distingue del entrenamiento que entraña más bien la ejecución de una serie de habilidades que exigían un trabajo físico-corporal (herrería, arte militar, navegación, agricultura, cacería, tejido, medicina...) como el de los animales de carga, a los que precisamente se les puede «amaestrar» o «entrenar», pues son sujeto de hábitos, como caballos, perros y aves.

Leibniz parte de este mismo principio en que se basan las Artes Mecánicas: los animales aprenden fácilmente, incluso se sirven de su naturaleza mejor que los humanos ${ }^{4}$. Por eso, quienes tienen a su cargo la educación de los niños, harían bien, según él, en aprender ciertas técnicas de quienes entrenan a los animales para lograr sus objetivos. Pues en cuanto a la naturaleza corporal se refiere, ésta funciona tanto en los animales como en los niños. Por ejemplo, el principal instrumento con

3 Cfr. Ricardo Da Costa, «Las definiciones de las siete artes liberales y mecánicas en la obra de Ramón Llull», en Anales del seminario de historia de la filosofía, vol. 23, p. 135-136; E. Colomer, «Las artes liberales en la concepción científica y pedagógica de Ramón Llull», en Arts libéraux et Philosophie au Moyen Âge, Actes du Quatrième Congrès Internacional de Philosophie Médiévale, p. 690; Christian Kopff, The Devil Knows Latin: Why America Needs the Classical Tradition, p. 99-100.

4 «Los animales se sirven de su naturaleza mejor que los humanos. Plinio refiere el caso de un elefante que caminaba sobre una cuerda. También en las cartas de Justo Lipsio se dispensan elogios a elefantes y perros» (NM, I, §4, p. 267-268, Zunner). 
que contamos para con los animales, según Leibniz, es el alimento. Por eso, cuando nos obedecen, solemos premiar tanto a niños como a animales con abundante comida; y cuando no obedecen, se les niega el alimento ${ }^{5}$.

De estas afirmaciones no debe entenderse naturalmente que Leibniz niegue la existencia de diferencias esenciales entre animales y niños, o entre entrenamiento animal y educación humana. Tan sólo quiere señalar, basado en un elemental sentido de observación empírica, de procesamiento de la experiencia por parte de la razón, que aquello de lo que nos servimos para inculcar ciertos hábitos a los animales, puede funcionar también en los niños, principalmente cuando se trata de arraigar destrezas de naturaleza corporal, pues el entrenamiento se aplica tanto a animales como a humanos. Leibniz deja ver incluso que si de lo que se trata es de imprimir un sentimiento específico o una emoción desde la niñez —que más adelante pueda ser útil a la razón cuando el individuo haya alcanzado la madurez-, entonces también puede ser válido recurrir a este sistema de recompensas y castigos, sólo que en tal caso, en lugar de ofrecerles alimentos corporales, se les deberá premiar con algún alimento espiritual, como por ejemplo, otorgarles algún reconocimiento público ante sus compañeros, elogiarlos ante los demás, etcétera ${ }^{6}$.

Todo lo que aquí menciona Leibniz, revela algo que para Aristóteles ya era conocido: que el hombre es sujeto de hábitos. La novedad sobre la naturaleza del hábito es que Leibniz considera que aquello que lo define es «la cantidad con que se produce una acción» ${ }^{7}$. Esta cantidad puede ser

5 «¿Quién ha logrado que los cuervos saluden, que las urracas hablen? Ciertamente el arte, pero también el estómago ("venter") generador de talento, creador de voces para las que tales animales estaban negados (...) De igual forma, cuentan que los pueblos de las islas Baleares en España no daban alimentos a sus niños hasta que hicieran lo que se les pedía. Y, por eso, aún hoy: los maestros atraen con bombones a los niños, para que acepten aprender las primeras letras, o aplican a los niños pena de ayuno, como costumbre en ciertas escuelas cuando se celebran banquetes» (NM, I, §6, p. 270, Zunner).

6 «A los niños será lícito (...) premiarles con algún alimento espiritual (...). Por eso, mientras que en las escuelas públicas el linaje es sólo una cuestión de clase y posición social, en las Academias más importantes es un estímulo para ascender en dignidad y prestigio. Antiguamente, por ejemplo, los niños que lograban destacarse como buenos estudiantes permanentemente, eran coronados por el resto de los niños y llevados a su casa con honores, según consta en Cicerón» (NM, I, \$7, p. 270, Zunner).

7 NM, I, §10, p. 271, Zunner. 
extensiva o intensiva. La extensiva consiste en la multitud de veces que se realiza una acción, y la intensiva se identifica con su intensidad es decir, con la fuerza con que se realiza. Ambas cantidades son importantes para que se imprima un hábito.

Para explicar la importancia de la cantidad extensiva, Leibniz señala varios ejemplos con los que además demuestra su enorme conocimiento de la tradición clásica ${ }^{8}$. La repetición sucesiva de un acto en la misma dirección es un ingrediente fundamental de la educación precisamente porque sin perseverancia no se produce la doctrina, hábito intelectual con que cuentan los sujetos pensantes para aprender por su inteligencia determinados objetos de conocimiento. Para aprender intelectualmente hay que repetir, pues como afirma el adagio inglés, practice makes perfect.

Por su parte, la necesidad de cantidad intensiva se hace manifiesta en educación porque de nada serviría repetir si lo repetido no se graba en el espíritu con la fuerza o intensidad suficiente para que se imprima. Así, por ejemplo, puede suceder que una sola acción realizada con singular fuerza de impacto produzca mejores resultados que la repetición constante de una acción sin la debida fuerza. Por eso, nos acordamos fácilmente de un hecho singular, de una broma inesperada, de un suceso afortunado, o de lo que nos acarreó alabanza o nos produjo vergüenza.

Después de todo esto se verá, clara para Leibniz, la necesidad de graduar de menor a mayor dificultad tanto la cantidad extensiva con que se aprende un hábito así como la intensiva. Esta graduabilidad se logra

8 «Ovidio afirmaba que: una gota perfora una roca/un anillo se gasta por el uso/y la reja ganchuda del arado/se gasta al contacto con el suelo. A esto mismo se refiere la tortuga de Esopo, más rápida que el águila, así como el proverbio alemán "quien va despacio, también cumple" (wer langsam geht, kommt auch nach). De todo esto surgió aquella habilidad de la raza humana para acometer por partes aquello que siendo afrontado como un todo sería insuperable. Así, por ejemplo, desgarramos bloques de mármol con lima, transportamos cerros enteros a base de cestas, vaciamos lagos mediante cubos. En aritmética, realizamos sumas inmensas procediendo por partes, y en geometría, partimos terrenos a base de triángulos» (NM, I, §11, p. 272, Zunner). 
especialmente si, comenzando con algo sencillo, aumentamos poco a poco la acción hasta lo máximo ${ }^{9}$.

\section{REQUISITOS LEIBNICIANOS DE LA ENSEÑANZA}

Después de hablar de cómo se adquiere un hábito entre aquellos seres que carecen de razón, incluyendo por supuesto a los animales, Leibniz trata después del modo como es adquirido un hábito entre los seres racionales, a quienes pertenece un particular tipo de habituación conocido como enseñanza, pues:

Enseñar es producir un hábito en un sujeto pensante o a través del pensamiento. $\mathrm{Y}$ al arte entero de enseñar se denomina didáctica. Incluso, quienes aprenden espontáneamente se enseñan a sí mismos, de ahí que sean llamados autodidactas ${ }^{10}$.

El sujeto de la enseñanza es un sujeto que enseña (docet), por lo cual se le llama docente, por contraposición con el que aprende (discet), que por

9 Leibniz señala diversos ejemplos tomados de las distintas disciplinas por él estudiadas: «Milón tenía un pequeño becerro al que acostumbraba transportar con sus manos hasta determinado lugar. Así lo hacía cada día. Y a medida que crecía el becerro, crecía con ello su peso; pero también la propia fuerza física de Milón sin que él lo advirtiese. Fue tal el grado de fortaleza adquirido que durante unos Juegos Olímpicos llegó al extremo de cargar un inmenso toro ante el asombro de toda Grecia. La misma situación puede aplicarse al arte de beber. Así lo supuso cierto poeta elegíaco llamado Cneo Cornelio Galo, quien conociendo que los germanos estaban acostumbrados a añadir poco a poco cierta clase de ácidos transparentes a las aguas que bebían, creyó que era parte de un pasatiempo para bebedores, digamos, un "club etílico" (eine Sauf Schule), en el que los germanos comienzan aprendiendo a beber en agua lo que después habrán de beber con el vino. Asimismo, los niños pasan de leer letras a leer sílabas y de leer sílabas a leer finalmente palabras. Y en aritmética, cuanto más se recorren los números (series de dígitos) hacia la izquierda, tanto más crecen en razón de 10. De manera análoga, si se trata de aprender de memoria algún pasaje, lo más apropiado es dividirlo en oraciones procediendo a la memorización gradual de cada una de ellas: en primer lugar se recita la primera oración, después la primera junta con la segunda, enseguida la primera y la segunda junto con la tercera, y así sucesivamente hasta agotar el pasaje (...) Con este sistema resulta sorprendente lo fácil con que puede aprenderse completamente de memoria algo» (NM, I, §15, p. 273-274, Zunner).

${ }_{10}$ NM, I, §16, p. 274, Zunner. 
eso se le llama en latín discente o discipulus, y en griego mathetés, de donde viene justamente la palabra matemática, que propiamente significa disciplina. Cuando no sólo enseña de hecho, sino que posee el título de docente en un grado superior o comparativo, se le llama doctor («más que docente»). Lo ordinario es que un doctor sea docto, que en latín significa sabio. A falta de doctores, podemos servirnos de documentos, que son los «medios» (-mentos) a través de los cuales se nos «enseña» (docu-) algo respecto a una materia en particular.

Pero lo verdaderamente relevante del ejercicio docente es -además del mathetés, es decir, la persona, diría Tomás de Aquino- lo que es objeto de enseñanza (el máthema), es decir, la doctrina, el cuerpo de verdades. La doctrina, cuando verdaderamente es tal, es provechosa para el alma. Y como según Leibniz la doctrina se compara al alma como la medicina al cuerpo ${ }^{11}$, lo lógico es que los requisitos que persigue la medicina sean los mismos que debe cubrir la enseñanza para ser realmente tan provechosa al alma como la medicina lo es al cuerpo. Concretamente, así como la medicina persigue «curar» de modo seguro (tutò), pronto (citò) y agradable (jucundè), el que enseña también debe hacerlo de esa misma manera, es decir, segura, pronta y agradable. De estos tres requisitos de la enseñanza, el primero se refiere al hábito mismo y los restantes al modo más conveniente de inculcarlo.

1. La enseñanza segura, según Leibniz, abarca dos cosas: a) que sean enseñadas cosas verdaderas, y b) que sean implantadas con firmeza, para que no se olviden con facilidad, pues también la medicina se esfuerza por evitar que rebrote o reaparezca una enfermedad. Para que sean implantadas con firmeza debe recurrirse a la cantidad extensiva (multitudo, le llama en latín) es decir, se debe realizar varias veces la acción que se desea implantar.

Para tal fin, Leibniz considera útil realizar de vez en cuando una especie de «corte de caja» o «inventario intelectual», i.e., una revisión

${ }^{11}$ "Quemadmodum autem Medicina se habet ad animalis corpus, ita Doctrina ad animam» (NM, I, §17, p. 274-275, Zunner). 
frecuente de lo aprendido en medio del camino y de la vida, a fin de evitar que queden sepultadas nuestras enseñanzas por la fuerza del olvido inconsciente.

Para ejemplificarlo, apunta el caso de los pitagóricos en la Antigüedad, quienes aconsejaban que nadie se fuera a dormir cada noche sin antes haber realizado un breve recuento de las cosas aprendidas a lo largo del día; también consideraban que era perjudicial para la memoria dejar de repasar lo aprendido más de un año, como sucede comúnmente en las escuelas, en las que mucho de lo conocido por los alumnos acaba enterrado tras el paso del tiempo por su inutilidad. Por eso, al llegar la noche, Leibniz menciona la conveniencia de analizar y recordar brevemente lo aprendido durante el día (algo parecido a un «examen de conciencia»). En la misma tendencia, al concluir cada semana, convendría volver a recordar aquellos aspectos más esenciales aprendidos durante la misma, ya se trate de aquellos hechos que más hayan llamado nuestra atención o los que consideremos más aprovechables para nuestro espíritu. Y así sucesivamente: al concluir el mes, conviene asimismo reflexionar sobre lo esencial de las semanas, y cada fin de año acordarse de lo esencial de cada mes, recordando y recapitulando las cosas más notables y, por supuesto, las más importantes de ser retenidas en nuestro espíritu.

2. Para una educación pronta, es decir, sin que haya que esperar mucho antes que el discente adquiera el hábito, lo más adecuado es recurrir a la cantidad intensiva (magnitudo, le llama en latín), es decir, realizar la acción con la fuerza suficiente.

3. Enseñar de modo agradable, último requisito propuesto por Leibniz, nos recuerda al célebre sermón que santo Tomás de Aquino pronunció durante su primera lección como maestro de teología en París ${ }^{12}$, y se

${ }_{12}$ «El erudito, cuando expone lo que sabe, debe hacerlo de manera que: 1) enseñe, 2) que deleite, y 3) que se acomode: a) a los ignorantes para enseñarles, b) a los que se aburren para deleitarlos y, c) a los perezosos para estimularlos»: Tomás de Aquino, Hic est liber mandatorum (sermón aparentemente auténtico pronunciado por Tomás, probablemente durante el dies legibilis o primera lección tras de su promoción como maestro de teología en la Universidad de París, en la primavera de 1256, según se desprende de James Weisheipl, Tomás de Aquino: vida, obras y doctrina, Eunsa, Pamplona, 1994, p. 427). 
refiere a la validez de suministrar placer con el fin de aprender. Quienes se encuentran en excepcional situación para adquirir el hábito de conocer placenteramente, manifiestan ser más capaces que los demás seres para aprender.

El punto es que según Leibniz, el educador puede servirse conscientemente de esta circunstancia suministrando a los seres susceptibles de ello, placer cuando aprenden, o dolor cuando, teniendo la capacidad para aprender, se niegan a escuchar. Esto se ve más claro si se trata de animales, en los que mediante alimento y caricias se logra que aprendan cosas que no están en su naturaleza, sino que más bien pertenecen a la naturaleza humana (el que un loro hable, el que un elefante se pare sobre una cuerda, el que un perro baile en una silla...). Y si se trata de humanos, ofreciéndoles algo que necesiten (por ejemplo comida) y sobre todo mediante recompensas espirituales (pabula animi), halagándolos o reconociéndolos ante los demás, como ya se mencionó al hablar del entrenamiento.

\section{EJEMPLOS DE DIMENSIÓN LÚDICA EN EL APRENDIZAJE}

Vinculado con el tema del placer aplicado al ejercicio de la enseñanza ${ }^{13}$, Leibniz se refiere al tema del juego como parte esencial del proceso educativo. Para mostrar su eficacia, cita el caso de un profesor de hebreo llamado Wilhelmus Schickardus, quien diseñó un magnífico sistema para enseñar la lengua hebrea por medio de su reloj, basado en el número 12. Schickardus enseñaba a los niños la gramática hebrea repartiendo sus distintas partes entre los alumnos, de tal modo que a unos les asignaba las reglas del nombre, a otros las del pronombre, a unos una parte de la sintaxis y a otros otra parte de ella. Además, distribuía un breve vocabulario entre ellos, asignando a algunos la memorización de palabras que comenzaran con la letra Halef (alfa), a otros con Bet (beta), Guimel (gamma), Dalet (delta), etcétera. Así, mientras uno recitaba, los demás atendían a la

${ }^{13}$ Jugar es placentero. Esto lo entendían bien los romanos, para quienes la palabra broma, pasatiempo, se decía jocus (de donde por romanceamiento se llegó en castellano a «juego») y agradable se decía jucundus. En este sentido, vale decir que para ellos todo jocus era jucundus. 
parte que les correspondía y finalmente todos aprendían jugando. Por esta razón, e incluso hoy, desde la perspectiva leibniciana, convendría asignar en las escuelas, no la realización de una misma cosa todos, sino distribuir la lección del día entre cada uno de los alumnos los cuales, finalmente trabajando juntos, llegarían además a conocerse mejor y llevarse mejor entre sí.

\section{Señala Leibniz:}

Los medios de aprendizaje serán agradables si al enseñar se juega, como lo consiguen en tan excelente manera las Comedias y las Fábulas. Con el mismo fin se han elaborado pequeños escritos recreativos de Geografía, Astronomía, Historia, Quiromancia, etcétera, así como dados con las letras del alfabeto, de las que da cuenta san Jerónimo a Paulina. Asimismo, chistes, epigramas, pinturas, canciones, poemas, cuadernos de apuntes. A ello pertenecen, por ejemplo, la notable Ética en imágenes, destinada a un joven principal de Altemburgo ${ }^{14}$, a quien le enseñaron cuál era su destino con mostrarle únicamente un puñado de tierra ${ }^{15}$; el libro de los Emblemata Moralia de Alciato; la Idea de un príncipe político cristiano de Saavedra ${ }^{16}$; la Teologia in schola cordis de Hatten, y aquel ingeniosísimo juego del que hace mención Christian Rosenkreutz en sus famosas Nuptiae Chymicae ${ }^{17}$, en el que, al igual que en el chaquete ${ }^{18}$, las virtudes vestidas de hábito blanco se

${ }^{14}$ Con este nombre se conoce a varias ciudades de Alemania.

${ }^{15}$ Recuérdese el conocido versito latino que ilustra esta misma enseñanza con la que se compara el fin o destino corporal del ser humano a polvo, tierra o cenizas, especialmente la última parte: Quid est homo? Homo, humus. Fama, fumus. Finis, chinis: el hombre es arcilla, su fama es humo y su fin es ser ceniza.

${ }^{16}$ Leibniz se refiere a Diego Saavedra Fajardo (1584-1648), natural de Murcia, quien estudió en Salamanca y llegó a ser diplomático. Fue autor de un tratado de educación de príncipes titulado República literaria o idea de un príncipe político cristiano, representada en cien empresas (Mónaco, 1640).

17 Se trata de las Bodas químicas (Nuptiarum Chymicarum Fratris Christiani Rosencreuz), escrito que durante la época de Leibniz (al igual que la Fama Fraternitatis y la Confessio), adquirió enorme resonancia a partir de 1615 en Europa. Hablan de un misterioso adepto medieval, Christian Rosenkreutz, quien aparentemente habría conseguido las más altas iniciaciones y dejado en su sepulcro — escondido en la Selva Negra alemana- todo cuanto los sabios antiguos llegaron a conocer en materia de alquimia, sabiduría esotérica y magia. Cfr. F.A. Yates, The Rosicrucian Enlightenment, London, 1972, y más recientemente de Maximo Introvigne, Los illuminati y el priorato de Sión, Madrid, Rialp, 2005.

${ }_{18}$ El chaquete, del francés jacquet (Ludus Latruncularius), tal como indica el propio Diccionario de la Real Academia Española, consiste en el juego de las tablas reales (Ludus Latruncularius) introducido a otras naciones desde Francia, bastante parecido al ajedrez. 
enfrentaban alternativamente y con admirable ingenio a los vicios vestidos con hábito negro ${ }^{19}$.

Esta idea tan apreciada por Leibniz, de servirse del juego para aprender cosas que de suyo podrían resultar no tan agradables, guarda estrecha relación, como es sabido, con la dimensión educativa del placer, a la que hace alusión Aristóteles al decir que:

Guiamos la educación de los jóvenes por el placer y el dolor. También parece que disfrutar con lo que se debe y odiar lo que se debe contribuyen en gran medida a la educación moral. Porque esto se extiende durante toda la vida, y tiene influencia para la virtud y también para la vida feliz, ya que todos los hombres escogen deliberadamente lo agradable y evitan lo molesto ${ }^{20}$.

El tema de la diversión (paidiá en griego, no por casualidad de la misma raíz de paidós, niño) no fue ajeno a Aristóteles, quien aunque estaba consciente de que la felicidad no está en la diversión, porque la felicidad es el fin del hombre, y «sería absurdo decir que la diversión es el fin de la vida humana» ${ }^{21}$, lo cierto es que ni Aristóteles ni Leibniz dudan de los efectos beneficiosos del entretenimiento, el juego y la diversión. Porque «la diversión es como un descanso» ${ }^{22}$, y aunque trabajar para divertirse es necio e infantil, en cambio «divertirse para trabajar mejor después, como dice Anacarsis, está bien» ${ }^{23}$.

Pero en Leibniz no se trata de servirse de la diversión porque ello permite trabajar mejor después, sino porque contribuye a la enseñanza misma, potenciando la capacidad de asimilación de contenidos visuales y auditivos. Así, por ejemplo, afirma el filósofo alemán que:

Las palabras memorizables no son las que escuchamos sin más, sino las que escuchamos con gusto: como la letra de las canciones y los poemas, o

9 NM, I, §13, p. 273, Zunner.

${ }^{20}$ Aristóteles, Ética Nicomáquea, 1172a 21-26, p. 270.

${ }^{21}$ Ibídem, 1176b 30, p. 285.

${ }^{22}$ Ibídem, 1176b 36, p. 286.

${ }^{23}$ Ibídem, 1176b 35, p. 285. 
los términos «pegajosos» (clappantes), como comúnmente se les llama, que se introducen con gran facilidad en el vocabulario de algunos niños (...) Es sorprendente cuánto pueden servir a este propósito las semejanzas que puedan descubrirse entre las diversas lenguas y la afinidad entre sus vocablos ${ }^{24}$. Pero aún más memorizables que las notas captadas por el oído son las notas percibidas por la vista, a las que pertenecen por ejemplo los jeroglíficos de los antiguos egipcios (o de los chinos modernos) a los que se refiere Kircher ${ }^{25}$ en su Oedipus Aegyptius. Asimismo, ayuda también a memorizar el disponer las cosas por casillas en una parte de la habitación de fácil acceso, y la distribución del resto de las cosas en determinados lugares, como lo aconsejan los especialistas en Mnemómica, entre quienes figuran en primer lugar, Juan Enrique Alstedio ${ }^{26}$ con su Thesaurus Mnemonicus; Jano Cecilio Frey ${ }^{27}$ con su Via ad divas scientias, artesque, y añádese a éstos Johannes Justus Winckelmann con sus Historiarum adumbrationes per picturas, obras realmente apreciables ${ }^{28}$.

${ }^{24}$ Lo que confirma la importancia de continuar cultivando el estudio de las etimologías griegas y latinas, principalmente entre quienes hablan las lenguas romances.

${ }^{25}$ Leibniz cita aquí al célebre jesuita alemán, que además de matemático, arqueólogo y filólogo fue un célebre egiptólogo: Athanasius Kircher (n. Fulda, 1601-1680), autor de una obra titulada Oedipus Aegyptiacus (Roma, 1652). Se trata de un texto ecléctico de la época renacentista inspirado en la astrología caldea, la cábala hebrea, la matemática pitagórica y la alquimia árabe. Se dice que ayudó a Bernini en la erección de un obelisco egipcio en la Plaza Navona de Roma y en la construcción de la fuente existente en dicha plaza. Al igual que Pico della Mirandola o Marsilio Ficino, Kircher trató de justificar la sabiduría del mundo pagano precristiano ante al mundo católico. A propósito de él, cfr. J. Gutmann, Athanasius Kircher und das Schöpfungs und Entwicklungs problem, Fulda, 1938; P. Friendlander, «Athanasius Kircher und Leibniz. Ein Beitrag zur Geschichte der Polystorie im XVII Jahrh» en Atti della Pontificia Accademia Romana di Archeologia, Rendiconti, 1937; McCraken, «Athanasius Kircher's universal poligraphy» en Isis, 1948, p. 215-228.

${ }^{26}$ Johannes Henricus Alstedius o Alsted (1588-1638): escritor protestante alemán. Durante un tiempo fue profesor de filosofía y teología en Herborn, Nassau y posteriormente en Weissenburg (actualmente Alba Iulia) en Transylvania (Rumania), donde permaneció hasta su muerte. Fue un escritor prolífico y quizá la más apreciada de sus obras sea su Enciclopedia (1630), cuyo nombre completo era Encyclopaedia septem tomis distincta (Herborn, 1630).

${ }^{27}$ Janus Caecilius Frey (1581-1631): filólogo suizo. Posteriormente estudió medicina a edad avanzada y llegó a ser médico de María de Médici. Autor de Via ad divas scientias, artesque, linguarum notitiam, sermones extemporaneos, nova et expeditissima.

${ }^{28}$ NM, I, §23, p. 278-279, Zunner. 
Lo anterior sólo confirma la necesidad leibniciana de recurrir a imágenes más plásticas y descriptivas procedentes de los sentidos externos e internos, que sirvan de apoyo propedéutico al conocimiento intelectual cuando las facultades intelectuales no han alcanzado todavía su pleno desarrollo, algo que también encuentra sustento en la teoría aristotélica del conocimiento, según la cual se considera, como es de todos conocido, que nada hay en el intelecto que no haya pasado primero por los sentidos.

\section{HACIA EL PLAN IDEAL DE ESTUDIOS SEGÚN LEIBNIZ}

El último tema al cual se refiere Leibniz, y con el cual concluyen sus observaciones de carácter más pedagógico que filosófico, se refiere, no precisamente con lo que puede aprender un niño, sino más bien a lo que, a juicio de Leibniz, debería de aprender en específico.

a) La primera asignatura que un niño debe aprender es la lengua. Pero no sólo la lengua propia o nativa, sino además, por su enorme difusión en su momento, la lengua latina ${ }^{29}$, a partir de la cual es posible, una vez que se la conoce, aprender diversas lenguas modernas: como francés, italiano, portugués, catalán y rumano, las cuales guardan estrecha relación morfológica con el latín (no en vano, franceses e italianos se disputan el honor de ser los mejores romanistas del mundo).

A algunos siglos de distancia de Leibniz, hoy podríamos decir que, dada la enorme importancia que ha adquirido el inglés, no sólo desde el punto de vista comercial, sino además cultural, por servir de puente entre las diversas etnias del orbe, bien podría éste fungir como una lengua sucedánea del latín.

Sobre el método que conduce a este aprendizaje multilingüe $a b$ infantia claramente señala Leibniz que:

Esto se logrará si se destina cierta parte del día para una lengua y otra parte del día para otra lengua, como por ejemplo, la mañana para que los

${ }^{29}$ NM, I, §39, p. 289, Zunner. 
alumnos hablen en latín con su profesor, y el mediodía para que las criadas hablen en lengua propia con sus señoras. Por este método, Albericus Gentilis consiguió que su pequeño hijo aprendiera tres lenguas al mismo tiempo. El niño hablaba con su padre en latín, con su madre en francés y con los sirvientes en inglés, que era la lengua vernácula del niño. Que otra parte de su tiempo lo dedique el niño al estudio del lenguaje corporal. Para ello conviene que conviva diariamente entre hombres cultos y de buenas costumbres, a fin de que observándolos, avance rápidamente en este terreno. En tercer lugar, que estudie historia, tanto la universal, como la contemporánea de tipo sacro y civil ${ }^{30}$.

En resumen, antes de los cinco años sería sumamente recomendable enfatizar en el aprendizaje por parte del niño, del mayor número posible de lenguas habladas, en la asimilación del lenguaje corporal, y curiosamente en el estudio de historia no sólo universal y de México, sino además, historia de la Iglesia o de la religión, algo que, dicho por un partidario de la religión natural, es profundamente significativo. Como hoy sucede en naciones europeas como España, en que, a pesar de que una porción considerable de la sociedad se conduce en el terreno de la praxis religiosa bajo cierto escepticismo, no obstante en las escuelas de instrucción elemental continúa estudiándose la religión como un fenómeno cultural. De manera semejante, en la formación de la conciencia infantil no sería conveniente, según Leibniz, suprimir el estudio del fenómeno religioso, al menos desde el punto de vista histórico y de la influencia que las instituciones eclesiásticas y religiosas han ostentado en el destino político, social e incluso económico de las naciones.

b) Pero a partir de los seis años, es importante despertar en los niños la confianza en sí mismos, permitiéndoles que vayan tomando decisiones propias, i.e., que aprendan a apoyarse más en su recto juicio que en el de sus padres. Es a esta edad a la que conviene enviarlo por primera vez a la escuela, sitio en donde podrá descubrir todo un mundo ignoto hasta entonces para él. Sobre el tipo de escuela, y los principios específicos que no debería dejar de aprender en ella da constancia el siguiente pasaje:

${ }^{30}$ NM, I, §39, p. 289-290, Zunner. 
Cuando haya cumplido seis años de edad, envíesele a la escuela pública, donde aprenderá cosas de qué conversar y finalmente hará amistades duraderas de por vida. Que viva poco entre sus padres, para que aprenda a apoyarse en el recto juicio propio. Que acostumbre practicar ejercicios, música, baile, esgrima, tiro, pintura, y otras cosas necesarias o apropiadas para la vida; pero principalmente, que aprenda a hablar con elegancia. Que acceda a un conocimiento más profundo de la historia antigua, y que se ocupe con la mayor atención de la matemática, es decir, aritmética, geometría, óptica, estática y astronomía. De ciencias naturales inclúyanse sólo los nombres de plantas, minerales, árboles, animales e instrumentos mecánicos, es decir, todo aquello de lo que trata Ammos Comenio en su Orbis sensualium pictus, pero pintado con mayor cuidado e ilustrado con colores más convenientes. También conviene que practique ejercicios de composición, no sólo de ensayos, sino también de discursos e incluso de contemporáneos, es decir, de cartas escritas a los amigos que en parte son ficticias y en parte verdaderas. Muéstrensele temas de discusión, de memorización y de creación por medio del arte combinatoria ${ }^{31}$.

c) Después de los doce años de edad y hasta los dieciocho, Leibniz juzga importante incluir en la formación de los discentes, materias más relacionadas con lo que en la Edad Media se denominaban Artes Mecánicas ${ }^{32}$, es decir, con todo aquello para cuya ejecución se requiere de un trabajo más corporal que intelectual ${ }^{33}$. Asimismo, de la lectura de algunos pasajes se desprende que era un partidario de incluir materias relacionadas

${ }^{31}$ NM, I, §40, p. 290, Zunner.

32 «De los 12 a los 18 años de edad, al estudiante deberá dársele mayor independencia, tratando de que dependa no tanto de sus profesores cuanto de sus amigos. Que se le den a conocer los mayores misterios de la naturaleza y la ciencia, los fundamentos de las artes mecánicas, para que al menos a partir de ellos, conozca la materia, sus instrumentos, sus reglas principales y su valor» (NM, I, §41, p. 291, Zunner).

${ }^{33}$ La más antigua división de las artes mecánicas, comprendía: herrería, arte militar, navegación, agricultura, cacería, tejido y medicina. Posteriormente se añadieron: ars theatrica, baile y lucha. Raimundo Lullio en el siglo XIII inicia sus meditaciones divinas sobre las artes mecánicas que abarcan los siguientes profesionales: 1) mercaderes; 2) marineros; 3 ) juglares y trovadores; 4) pastores; 5) pintores; 6) labradores, y 7) unos treinta y cinco maestros de oficios, entre los más importantes en la Edad Media: herreros, carpinteros, albañiles, tapiceros, orfebres y acuñadores, escribanos, zapateros, sastres, peleteros, tejedores, barberos, carniceros, cazadores con trampas y lazos, tenderos, molineros, cristaleros, alfareros y aceiteros, horneros, hortelanos, taberneros, carteros, pregoneros, cambistas, trajineros, jugadores, ballesteros, corredores, calafates y transportadores. Cfr. Ricardo da Costa, «Las definiciones de las siete artes liberales y mecánicas en la obra de Ramón Llull» en Anales del Seminario de Historia de la Filosofía, vol. 23, p. 135-136. 
con lo que hoy denominaríamos «cultura financiera para niños» ${ }^{34}$, algo de lo que ya no se puede prescindir y cuya impartición, desde los primeros años del infante, se juzga cada vez más necesaria.

Como el médico que contempla al hombre en toda su debilidad, como el jurista que lo percibe en toda su maldad, y como el teólogo que lo advierte en toda su estupidez, Leibniz cree sumamente deseable instruir al adolescente en los rudimentos de estas tres asignaturas, en las que encontrará valiosas herramientas para encarar la vida, ahí donde precisamente la enfermedad, el delito y el pecado, respectivamente, ejercen mayores perjuicios sobre los seres humanos:

Por otro lado, que aprenda rudimentos de medicina, de anatomía, el poder curativo de ciertas sustancias naturales, y los métodos de que disponen los químicos y quienes practican la farmacopea para la preparación de los medicamentos. Pues es deseable que cualquiera de los seres humanos sea en cierta medida médico, jurista y teólogo, es decir, que conozca con la mayor profundidad que le sea posible de medicamentos, de teología y a lo menos de jurisprudencia positiva. Que conozca los estatutos de la propia república y las leyes del reino, y no sólo las del propio reino, sino en alguna medida también las leyes de otros reinos, para que al viajar o vivir en el extranjero pueda hacerlo de la mejor forma. Que aprenda francés e italiano: y para que pueda escuchar la Sagrada Escritura, hebreo y griego de modo que le sea posible comprender el Viejo Testamento y el Nuevo Testamento ${ }^{35}$.

Sin dejar de reconocer los beneficios que produce practicar aquellas disciplinas que facilitan el ejercicio de la palabra hablada, como el teatro, la declamación (cada vez más en desuso en nuestros tiempos) y principalmente la oratoria ${ }^{36}$, Leibniz recomienda que los jóvenes entre doce y

${ }^{34}$ «Que también aprenda la naturaleza del comercio internacional, para que distinga entre las diversas mercancías, sepa su valor, y el lugar del que proceden» (NM, I, §41, p. 291, Zunner).

${ }_{35}$ NM, I, §41, p. 291, Zunner.

${ }^{36}$ «Que declame públicamente y participe en la representación de comedias. Pues, como justamente enseña Hugo Grocio, las demás artes rinden homenaje a la retórica, sólo cuando ésta logra aprovechar lo que ellas pueden proporcionarle. Practíquese la retórica no sólo en lengua latina, sino también en la lengua propia. Pero que principalmente sea practicada en aquella profesión en la que en ocasiones dará cuenta de sus dones. Que además aprenda en los mejores libros el conocimiento de las cosas que le procuran mayor utilidad» (NM, I, §41, p. 291, Zunner). 
dieciocho años, cultiven las relaciones humanas y que aprendan a relacionarse debidamente con las personas adecuadas. Pues para abrirse paso en un mundo competitivo, tan importante como la preparación técnica en los diversos campos del conocimiento, resulta ser la preparación humana que permitirá al joven cultivar las amistades necesarias para acceder a la vida profesional (quod est fundamentum hodie promotionis) ${ }^{37}$. Tanto hoy, como en pleno siglo XVII, no basta apelar a un criterio puramente «credencialista» para ser contratado, es decir, no es suficiente con ostentar los títulos expedidos por las escuelas para ingresar directamente a la vida laboral; conviene poseer algo más, algo que no se enseña necesariamente en las universidades ${ }^{38}$.

d) Finalmente, a partir de los dieciocho años, una parte importante de la formación de los jóvenes debe obtenerse a partir de sus impresiones de viaje, tomando nota en una especie de bitácora de viaje de aquellas costumbres o instituciones vigentes en el extranjero, pues como él mismo señala, el verdadero propósito de todo viaje es aprender, ampliar horizontes culturales, ensanchar el alma, y no precisamente acumular consumibles. El texto preciso con el que realiza esta recomendación, así como otras aplicables asimismo para quienes se dedican a viajar, es el siguiente:

Desde los dieciocho años (o si se es lento de entendimiento, desde los veinte años de edad hasta su egreso), conviene que el estudiante se dedique a viajar por el extranjero. Cuidando en ello su salud, que es de lo que trata el célebre tratado de Medicina para viajeros de Christophorus Schorerus, que observe y anote lo más conveniente en materia de alimentación, bebida, vivienda, agricultura e ingeniería, que se practica en alguna población. Observe también las leyes y las costumbres propias del

${ }^{37}$ «Que durante esta época de su vida, en vez de asistir a la universidad frecuente una academia o un palacio, y de no ser ello posible, que asista a un lugar prestigioso, en el que le sea posible gozar del conocimiento y amistad de los varones más notables, que actualmente es la base para abrirse paso en sociedad. ¿O acaso hay un camino más fácil para ocupar un oficio, una vez concluidos los estudios en la academia?» (NM, I, §41, p. 291292, Zunner).

38 «Antes era costumbre enrolarse en una universidad y solicitar de ella el certificado que acreditaba a un joven como recién egresado. Hoy el egresado debe reunir varias habilidades, razón por la que no conviene que las academias se instalen en ciudades pequeñas o poco conocidas» (NM, I, §41, p. 292, Zunner). 
lugar al que se viaja. Solicite información acerca de los varones notables, normalmente más fácil de proporcionar a los extranjeros que a los nacionales, principalmente datos de ministros y funcionarios. Si llegara a escuchar historias memorables o datos singulares referentes a ciencia o naturaleza, anótelas con todo cuidado. Así cumplirá el objetivo de todo viaje, que no consiste sólo en comprar cosas sino en adquirir conocimientos de otras regiones. Y si alguna otra región despunta en tecnología superior a la del propio país, procúrese aprenderla ${ }^{39}$.

Hasta aquí con la serie de recomendaciones de carácter pedagógico en general de Leibniz referentes a cuál debe ser la disposición de los estudios en general tanto para un niño como para un adolescente, e incluso para quien ronda los dieciocho años. Como él mismo establece al final de su obra, se trata de observaciones que considera útiles para proporcionar a los sujetos de la educación desde sus primeros años, los elementos que servirán de base para la configuración posterior de una carrera profesional, tomados no de autores pedagógicos propiamente, sino a partir de la reflexión de sucesos personales del autor, y a los que se refiere tangencialmente en diversas obras ${ }^{40}$, a partir de los diversos lugares y países ${ }^{41}$ en los que vivió.

${ }_{39}$ NM, I, §42, p. 292, Zunner.

${ }^{40}$ Para un elenco de los distintos lugares del corpus filosófico leibniciano en los que se tratan otros tópicos de interés pedagógico, puede consultarse: Alfred K. Tremel, «Von der besten aller moglichen Welten zur Welt voll besserer Moglichkeiten: Leibniz in padagogischer Sicht» en Studia Leibnitiana, 1991, p. 40-56.

${ }^{41}$ Datos interesantes sobre el esfuerzo de Leibniz por aplicar personalmente muchos de sus conceptos pedagógicos en Europa Oriental, principalmente en Rusia, con vistas a elevar el desarrollo cultural de esta nación, que acusó la fuerte influencia de la tradición francesa de la que el mismo Leibniz participó se hallarán en: A.T. Grigoryan, «Leibniz and Russia» en Organon, p. 195-208. 


\section{CONCLUSIÓN}

El modo de pensar de Leibniz ha influido decisivamente en la filosofía moderna, pero también es un hecho que la pedagogía moderna debe mucho a este pensador alemán; al menos de manera indirecta. No es éste el lugar para extendernos sobre el particular. Ello ameritaría un artículo más profundo. Pero la experiencia adquirida en París (muchos años después de haber escrito el Nova Methodus), cuando fungió como tutor del joven Phillip Wilhelm von Boineburg, le permitió aumentar su prestigio como educador de jóvenes nobles que aspiraban a prepararse para ocupar altos cargos públicos en la corte de los distintos monarcas europeos. Y todo cuanto prescribió para los príncipes era consistente con lo que había propuesto para cualquier clase de estudiante, ya sea noble o sin alcurnia.

Su propuesta general es que quien aspire a alcanzar la ciencia en cualquier campo de la realidad, debe hacer todo lo posible por ampliar los canales de información e instrucción personales, lo cual se logra procurando que desde los primeros años, los niños desarrollen una serie de destrezas (perfectamente compatibles con la doctrina aristotélica del hábito intelectual o moral), basadas en un sistema de recompensas y castigos, por un parte, y por otra, a partir de la multitud y magnitud de aquellos actos que se pretende arraigar en el sujeto a educar, sin olvidar que la educación como la medicina, están para corregir con verdadera eficacia aquellos aspectos que desentonen con una personalidad verdaderamente sana y robusta, física y anímicamente.

La firmeza y la eficacia del proceso educativo leibniciano dejan abierta la posibilidad de aprender diversos conocimientos, explotando el juego y el entretenimiento que Aristóteles ya había detectado como valiosos para el proceso formativo. Y aunque existe un gran silencio referente a la educación moral y religiosa, Leibniz juzga importante incluir la historia sacra y eclesiástica entre aquellas asignaturas que forman parte del plan de estudios ideal. En su calidad de rosacruz y partidario de una religión más afín con lo que se conoce como la Nueva Era, Leibniz está consciente de la importancia de desarrollar el sentido de lo divino, del orden en el cosmos y de la necesidad de un absoluto a partir del cual se explique la armonía establecida en la creación. 
En esta misma dirección programática, se enfatiza el desarrollo de la inteligencia matemática y principalmente lingüística desde los primeros años, sin excluir la posibilidad de explotar las conclusiones que disciplinas liberales como la lógica, la gramática en varias lenguas y la retórica puedan aportar para potenciar las facultades discursivas e intelectuales, más que cualesquiera otras de las que forman parte de la naturaleza humana, algo que, como podrá advertirse para quienes conocen de pasada la pedagogía de corte personalista o tomasiano, constituye tan sólo un aspecto importante de la formación de los individuos, pero no necesariamente el más importante de la educación de los afectos que propone Leibniz. Habrá que esperar su famosa Lettre sur l'Éducation d'un Prince escrita posteriormente (1686), para conocer aquellos otros aspectos de la personalidad de un discente que también merecen perfeccionarse además del intelecto, para conocer mejor las aportaciones del pensamiento moderno de Leibniz a la historia universal de la pedagogía. 


\section{REFERENCIAS BIBLIOGRÁFICAS}

ALSTEDIUS, Johannes Henricus, Encyclopaedia septem tomis distincta, Herborn, 1630.

AQUINO, Tomás de, «Hic est liber mandatorum» (texto latino) en Obras completas de Santo Tomás de Aquino, CD-ROM, Pontificio Ateneo Regina Apostolorum, Roma, 2001.

ARISTÓTELES, Ética Nicomáquea, Gredos, Madrid, 2000.

COLOMER, Eusebio, «Las artes liberales en la concepción científica y pedagógica de Ramón Llull», Arts libéraux et Philosophie au Moyen Âge, Actes du Quatrième Congrès Internacional de Philosophie Médiévale, Université de Móntreaul, Móntreaul/Paris, Canada, 1969, p. 690 .

DA COSTA, Ricardo, «Las definiciones de las siete artes liberales y mecánicas en la obra de Ramón Llull» en Anales del Seminario de Historia de la Filosofía, vol. 23, 2006, p. 135-136.

FREY, Janus Caecilius, Via ad divas scientias, artesque, linguarum notitiam, sermones extemporaneos, nova et expeditissima, Brösseln, Jena, 1674.

FRIENDLANDER, P., «Athanasius Kircher und Leibniz. Ein Beitrag zur Geschichte der Polystorie im XVII Jahrhundert» en Atti della Pontificia Accademia Romana di Archeologia, Serie III, XIII, S. 229247, Rendiconti, 1937.

GRIGORYAN, A.T., «Leibniz and Russia», Organon, vol. 7, 1970, p. 195-208.

GUTMANN, J., Athanasius Kircher und das Schöpfungs und Entwicklungs problem, Fulda, 1938. 
INTROVIGNE, Maximo, Los illuminati y el priorato de Sión, Rialp, Madrid, 2005.

KOPFF, Christian, The Devil Knows Latin: Why America needs the Classical Tradition, Wilmington, Intercollegiate Studies Institute, 1999.

LEIBNIZ, Nova methodus discendae docendaeque jurisprudentiae: ex artis Didacticae Principiis in parte Generali praemissis, experientiaeque Luce, Johannis Davidis Zunneri, Frankfurt, 1667, 364 p.

MCCRAKEN, George E., «Athanasius Kircher's universal poligraphy» en Isis, 39, 1948, p. 215-228.

MOREAU, J., «Leibniz a Paris» en Teoresi, vol. 31, 1976, p. 201-221.

SAAVEDRA FAJARDO, Diego, República literaria o Idea de un Príncipe político cristiano, representada en cien empresas, Mónaco, 1640.

TREMEL, Alfred K., «Von der besten aller moglichen Welten zur Welt voll besserer Moglichkeiten: Leibniz in padagogischer Sicht» en Studia Leibnitiana, 1991, p. 40-56.

WEISHEIPL, James, Tomás de Aquino: vida, obras y doctrina, Eunsa, Pamplona, 1994. 